\title{
Sexually transmitted diseases reported by STD services in the Netherlands, 1984-1990
}

\author{
H F Treurniet, W Davidse
}

\begin{abstract}
Objective-To present general trends in sexually transmitted disease (STD) in the Netherlands during the period 1984-1990 and to describe characteristics of the patients in order to get insight into possible factors underlying these trends. Methods-Since 1984 patients diagnosed with STD visiting STD clinics and local public health services in the Netherlands are reported by the nursing stafis. In addition to diagnosis and gender of the patient epidemiological background information is registered. The reported annual cases of gonorrhoea, syphilis and Chlamydia trachomatis infections are presented. Further, the epidemiological features of over 25,000 patients with infections due to Chlamydia trachomatis, gonorrhoea or syphilis infections were compared.
\end{abstract}

Results-During the period 1984-1990 an overall decrease in the total number of gonorrhoea infections was reported; among homosexual males; however, an increase in gonorrhoea rates and an increasing number of sexual partners after 1989 was reported. Furthermore, the percentage of gonorrhoea infections caused by penicillinase-producing Neisseria gonorrhoeae was found to be on the increase in various subgroups but not in homosexual males. Syphilis rates among females declined from 1984 to 1987 after which an increase was reported reaching a peak in 1989; syphilis rates among males peaked during 1989. After 1988 Chlamydia trachomatis infections increased which, however, is largely due to the introduction of screening among all visitors of the Amsterdam STD service resulting in improved casedetection. Finally, it appeared that STDs are not randomly distributed over the population but are associated with certain patient characteristics.

Conclusion-The data provided by STD services reveal an epidemiological pattern for STDs in the Netherlands. The increase in the reported number of gonorrhoea infections among homosexuals together with the increasing number of sexual partners among homosexual males suggest that group of highly sexually active individuals switch or return to higher risk behaviours. Further research is needed to determine the causes of the described trends and behavioural changes in order to undertake preventive activities.

(Genitourin Med 1993;69:434-438)
Introduction

For various European countries, among which are the United Kingdom, Sweden, Italy and Belgium, trends in STD have been published..$^{1-4}$ In these countries data are usually obtained from laboratory surveillance reports or the notification system, which often do not include epidemiological information. Until 1983 STD trends in the Netherlands were only available from the notification system while epidemiological background information was provided mainly by a large STD clinic in Amsterdam. ${ }^{56}$ Notified cases of gonorrhoea or syphilis are documented anonymously according to date and place of reporting. In order to obtain more epidemiological information about the incidence of STD, the Director of Health established an additional registry of sexually transmitted diseases (STDs) in 1983; this registry was to be maintained in addition to the system of statutory notification of specific diseases in the Netherlands. Data for this registry are collected by the nursing staffs of STD services all over the country; not only diagnosis and gender of the patient but also epidemiological background information are registered. This is the only longitudinal data collection system which includes epidemiological information relevant to STD in the Netherlands. In this article the data collected between 1984 and 1990 are presented. The purpose of this study was to explore general trends in STD in subgroups characterised by age, gender, sexual preference, number of sexual partners and prostitution; the detailed background information collected by STD service data give an insight into possible factors underlying the general trends.

\section{Materials and methods}

Registration of STD is carried out by the nursing staffs of 44 STD services (including local public health services and STD hospital clinics), located all over the country. The STD services in the major cities (Amsterdam, Rotterdam, The Hague, Groningen and Utrecht) together account for $69 \cdot 4 \%$ of the data of which the greater part $(42.0 \%$ of all data) is reported by the municipal STD clinic of Amsterdam. In the STD services cure, treatment, contact tracing and counselling are free of charge. Together with general practitioners and dermatologists (irrespective of whether they have hospital facilities), STD services represent the major portion of the health care network for patients with STD in the Netherlands. It has been estimated that $21 \%$ of the STD patients attend the STD services while $77 \%$ visit their general practitioner or dermatologist. ${ }^{7}$ These percentages 
Table 1 Number of cases of gonorrhoea, syphilis and Chlamydia trachomatis infections in the STD registry

\begin{tabular}{lrrrrrrr}
\hline Year & 1984 & 1985 & 1986 & 1987 & 1988 & 1989 & 1990 \\
\hline gonorrhoea & 9410 & 7266 & 5606 & 3079 & 1968 & 1971 & 1846 \\
syphilis & 861 & 643 & 504 & 391 & 399 & 512 & 422 \\
Chlamydia trachomatis infections & 1169 & 1812 & 2082 & 1917 & 1650 & 2132 & 1999 \\
\hline
\end{tabular}

may differ per STD service dependent on factors like location of the clinic, hours of opening and whether or not anonymous treatment is possible. In a large city like Amsterdam for example $50 \%$ of the cases of syphilis and gonorrhoea were found to receive treatment at the STD clinic. ${ }^{8}$

In the STD services data for registration are collected whenever a new case of STD is diagnosed and the patient has been referred to the nursing staff for health education and contact tracing. Each new diagnosis, irrespective of previous diagnoses, is registered as a new case of infection; in this article a registered case of infection therefore refers to new disease occurrence and not to a new patient. Duplicate registry is only possible if a person visits more than one clinic with the same episode or disease. Data collected from each patient include demographic, medical and behavioural characteristics (sexual preference, intravenous drug use, number of sexual partners, previous STD) and diagnosis. All forms are completed by hand and submitted to a central institute, the STD Foundation, where editing checks are performed and the data are entered into the computer. None of the 44 STD services retracted from data collection during the period under study. Since the trends in gonorrhoea and syphilis reported by the public health service of Amsterdam ${ }^{56}$

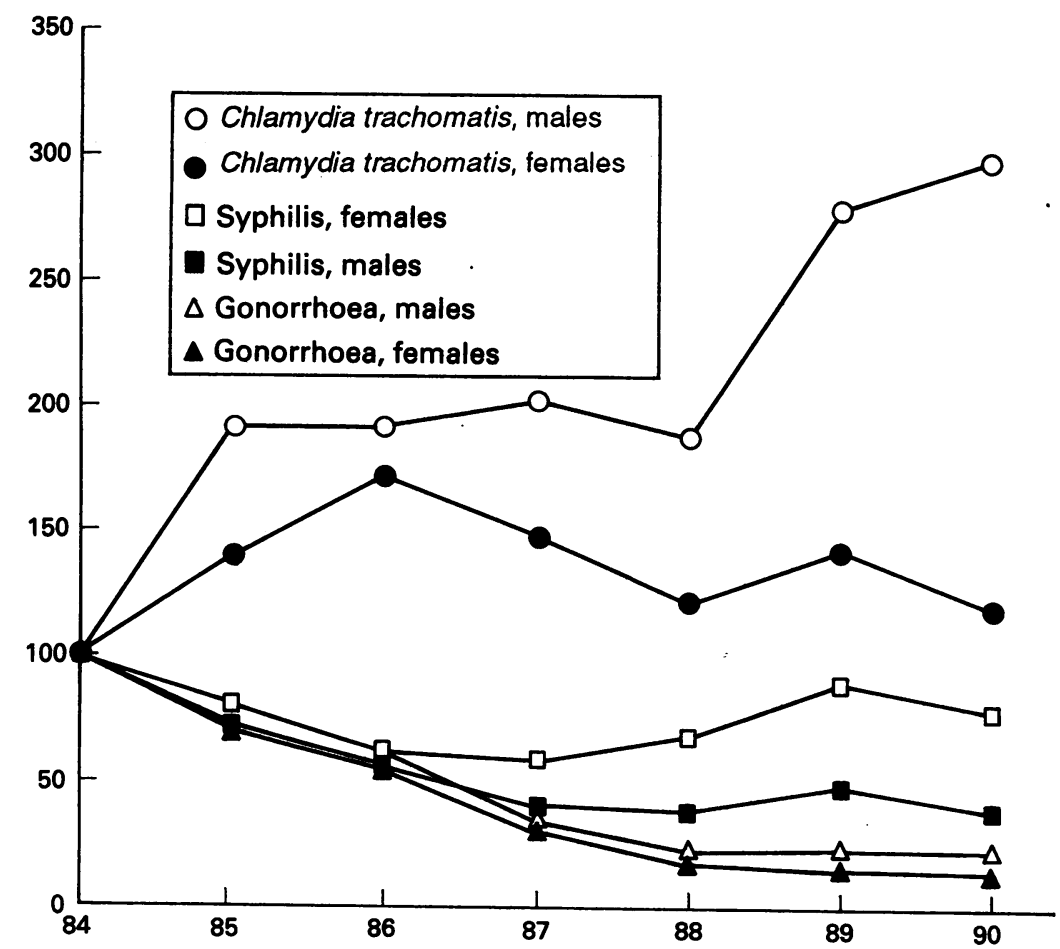

Figure 1 Annual numbers of gonorrhoea, syphilis and infections due to Chlamydia trachomatis according to gender, reported by the nursing staffs of STD services during the period 1984-1990, relative to the values in 1984: Gonorrhoea: 6054 males, 2256 females. Syphilis: 648 males, 213 females. Infections due to Chlamydia trachomatis: 337 males, 832 females. were comparable with the data provided by the miscellaneous STD services (results not shown) and the notification system, there is also no evidence of changes in organisation of STD services which might have affected the registration of these STDs. In contrast, working procedures with regard to Chlamydia trachomatis infections changed during the period under study: screening on these infections was introduced to all individuals visiting the STD service of Amsterdam resulting in an increase in the reported number of infections due to Chlamydia trachomatis. Before analysis of the registered data, the method of data collection was evaluated in order to determine the reliability of the reported data. ${ }^{9}$ For that purpose the nursing staffs of 17 STD services (together responsible for $80 \%$ of the data) were interviewed to get insight into the working methods in STD services, the procedure of completing the registration forms and its effects on the quality of the registered data. From the interviews it became evident that some variables (native country, site of infection, intravenous drug use and previous STD) were not filled in consistently; these variables were therefore excluded from the analysis. In this article the data are related to age, gender, sexual preference, number of sexual partners and prostitution; data about residence, acquisition and contact tracing were also recorded but are not presented. Since gonorrhoea, syphilis and infections due to Chlamydia trachomatis are the only STD registered by all STD services, only trends in these STDs will be presented; trends for the period 1984-1990 are given for the total group of patients as well as various subgroups. Finally the results of a comparison of 25,000 patients with infections due to Chlamydia trachomatis, gonorrhoea and syphilis are presented; the aim of this analysis was to discover whether the three STDs are randomly distributed over the patient population or whether they are associated with certain patient characteristics. The analyses were performed using SPPSX. ${ }^{10}$

\section{Results}

The registry contains data on 20319 female and 30911 male cases of STD. The total number of infections with syphilis and gonorrhoea or infections due to Chlamydia trachomatis in the registry has decreased: in 1990 the least number of STDs was registered (table 1).

Figure 1 shows that the number of infections with gonorrhoea declined between 1984 and 1989 and remained stable after 1989 among males; among females the declining rate extended over the whole period.

The cases of syphilis decreased from 1984 to 1987 but among females in 1988 an increase was reported reaching a peak in 1989; among males a peak in incidence was reported in 1989. In 1989 the number of Chlamydia trachomatis infections increased among both males and females; the registration of infections due to Chlamydia trachomatis, however, is known to be strongly 


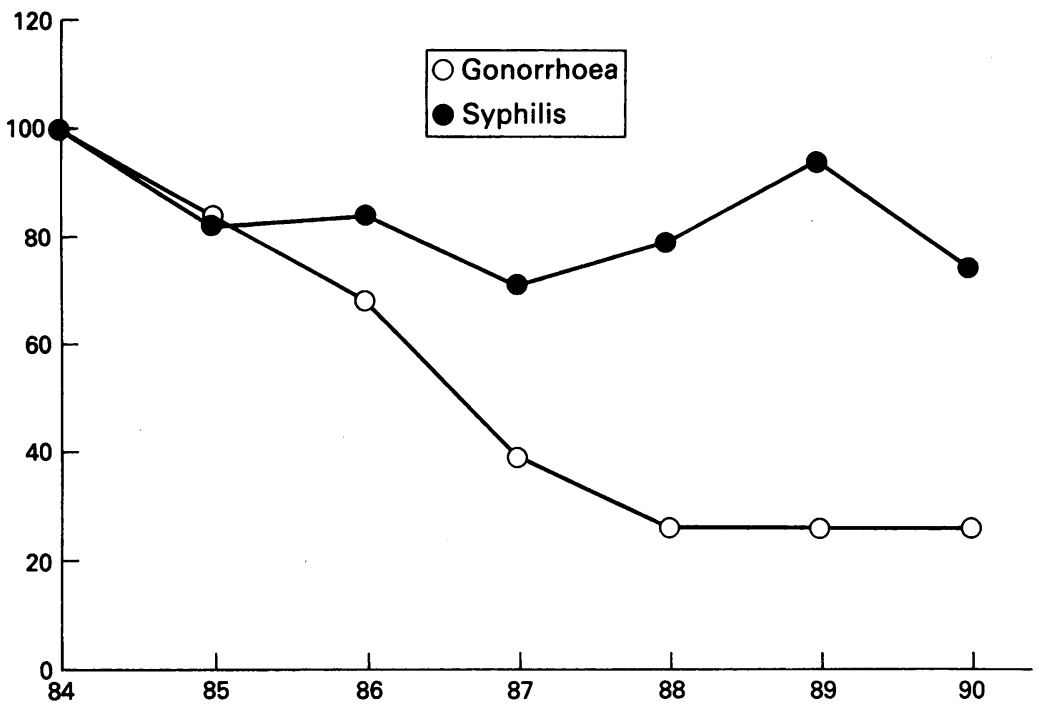

Figure 2 Gonorrhoea and syphilis among heterosexual males, reported by the nursing staffs of STD clinics during the period 1984-1990, relative to the values in 1984: 4608 with gonorrhoea, 228 with syphilis.

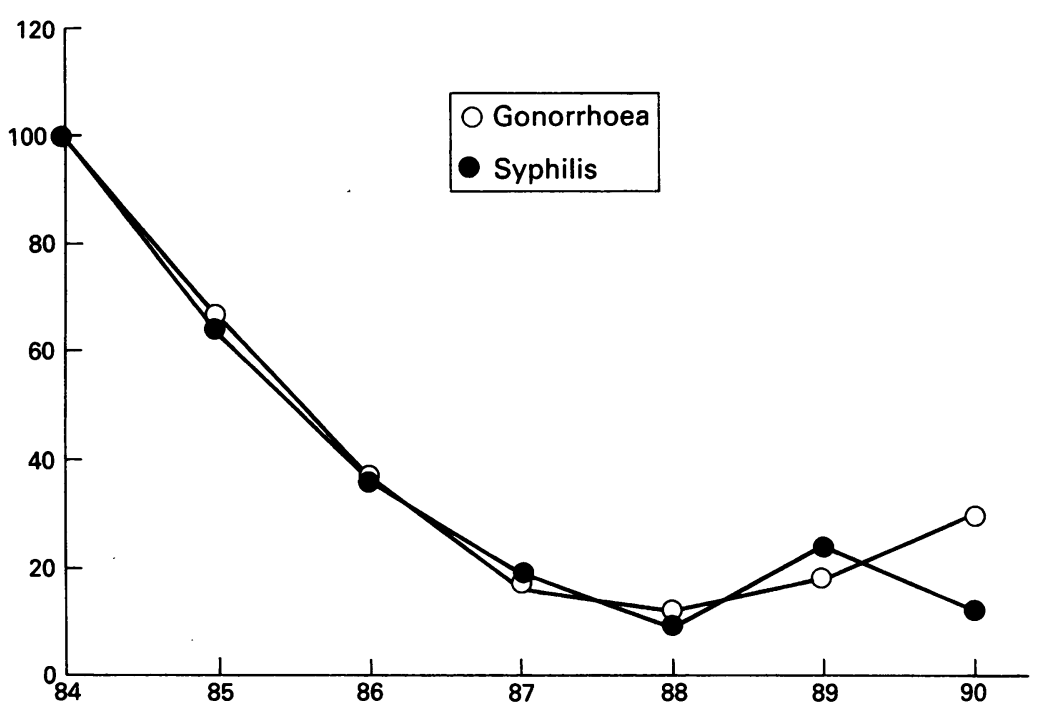

Figure 3 Gonorrhoea and syphilis among homosexual males, reported by the nursing staffs of STD services during the period 1984-1990, relative to the values in 1984: 952 with gonorrhoea, 334 with syphilis.

influenced by changes within STD services (see discussion) and therefore no further trends in this STD will be presented.

Figures 2 and 3 shows STD among heterosexual and homosexual males. After an increase in the number of syphilis infections among homosexual and heterosexual males in 1989, a decrease occurred in 1990. The number of heterosexually acquired gonorrhoea cases remained constant during the period 1988-1990; among homosexual males, however, a reversal of the downward

Table 2 Number of cases of gonorrhoea infections among homosexuals and heterosexuals and the proportion of penicillinase-producing Neisseria gonorrhoea (PPNG)

\begin{tabular}{cllll}
\hline Year & $\begin{array}{l}\text { Homosexual males } \\
\text { number (\% PPNG) }\end{array}$ & $\begin{array}{l}\text { Heterosexual males } \\
\text { number (\% PPNG) }\end{array}$ & $\begin{array}{l}\text { prostitute females } \\
\text { number }(\% \text { PPNG) }\end{array}$ & $\begin{array}{l}\text { Non-prostitute females } \\
\text { number }(\% \text { PPNG) }\end{array}$ \\
\hline 1984 & $952(1 \cdot 7)$ & $4608(7 \cdot 4)$ & $1582(5 \cdot 5)$ & $1774(4 \cdot 0)$ \\
1985 & $635(0 \cdot 5)$ & $3872(6 \cdot 3)$ & $1009(3 \cdot 3)$ & $1371(5 \cdot 3)$ \\
1986 & $350(3 \cdot 1)$ & $3146(9 \cdot 9)$ & $730(6 \cdot 7)$ & $1118(3 \cdot 7)$ \\
1987 & $151(4 \cdot 6)$ & $1781(9 \cdot 4)$ & $299(7 \cdot 0)$ & $703(9 \cdot 0)$ \\
1988 & $118(1 \cdot 7)$ & $1182(11 \cdot 0)$ & $180(3 \cdot 3)$ & $409(9 \cdot 0)$ \\
1989 & $174(1 \cdot 1)$ & $1194(23 \cdot 2)$ & $245(20 \cdot 8)$ & $343(13 \cdot 7)$ \\
1990 & $287(4 \cdot 2)$ & $1184(25 \cdot 6)$ & $230(24 \cdot 3)$ & $253(22 \cdot 1)$ \\
\hline
\end{tabular}

trend in gonorrhoea was found: from 1989 to 1990 the number of gonorrhoea infections increased by $65 \%$ (1989:174 and 1990:287). The proportion of penicillinase-producing Neisseria gonorrhoeae (PPNG) was markedly higher among heterosexual males than among homosexual males and was found to increase only among heterosexuals (table 2); the absolute number of PPNG infections increased only among homosexual males.

A decline in gonorrhoea rates was reported for both prostitute and non-prostitute females; in both groups the proportion of PPNG increased (table 2). After a decline in the number of female cases of syphilis, an increased number of syphilis infections was reported among prostitute females in 1989 (fig 4); among non-prostitute females the number of syphilis infections remained constant on average after 1987 (fig 5).

The proportion of homosexuals who reported having more than 10 different sexual partners (defined as the estimated number of partners during the period of contagiousness of the patient) increased from $35 \%$ in 1989 to $44 \%$ in 1990 . Of heterosexuals $29 \%$ reported having more than 10 different sexual partners in 1990 against $24 \%$ in 1989 (table 3).

To compare characteristics of patients with different STDs, a multivariate model was designed; using this model, the characteristics of patients with syphilis and infections due to Chlamydia trachomatis could be compared with the characteristics of patients with gonorrhoea. In the model 6910 patients with infections due to Chlamydia trachomatis were compared with 22780 cases of gonorrhoea; furthermore, 2532 cases of syphilis were compared with 23314 patients with gonorrhoea. Patients with more than one STD (2442 patients had both infections due to Chlamydia trachomatis and gonorrhoea, 130 patients had both syphilis and gonorrhoea) were excluded from the analysis. In table 4 the resulting odds ratios are presented. The first category is the reference category $(O R=1 \cdot 00)$.

The analysis revealed characteristic differences between patients with syphilis, infections due to Chlamydia trachomatis and gonorrhoea. Syphilis was encountered more frequently than gonorrhoea among older patients and females, male prostitutes, homosexuals and bisexuals; among female prostitutes gonorrhoea was more common than syphilis.

Chlamydia trachomatis infections were encountered more frequently in younger patients than gonorrhoea, and the infection was diagnosed more often in females. Furthermore, infections due to Chlamydia trachomatis were less common in prostitutes, homosexuals and bisexuals than gonorrhoea.

\section{Discussion}

The group of STD patients visiting their general practitioner is known to have other characteristics than those attending an STD service; in STD services for example special attention is paid to prostitute women and patients addicted to drugs. ${ }^{9}$ As the proportion 


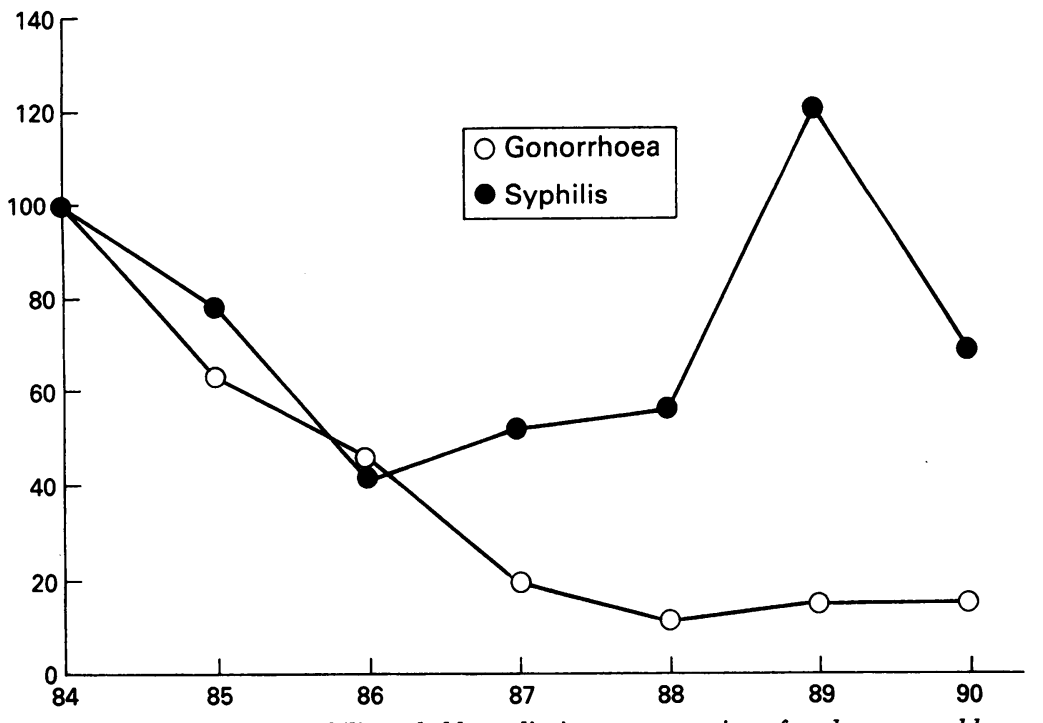

Figure 4 Gonorrhoea, syphilis and chlamydiasis among prostitute females, reported by the nursing staffs of STD services during the period 1984-1990, relative to the values in 1984: 1582 with gonorrhoea, 81 with syphilis and 167 with infections due to Chlamydia trachomatis.

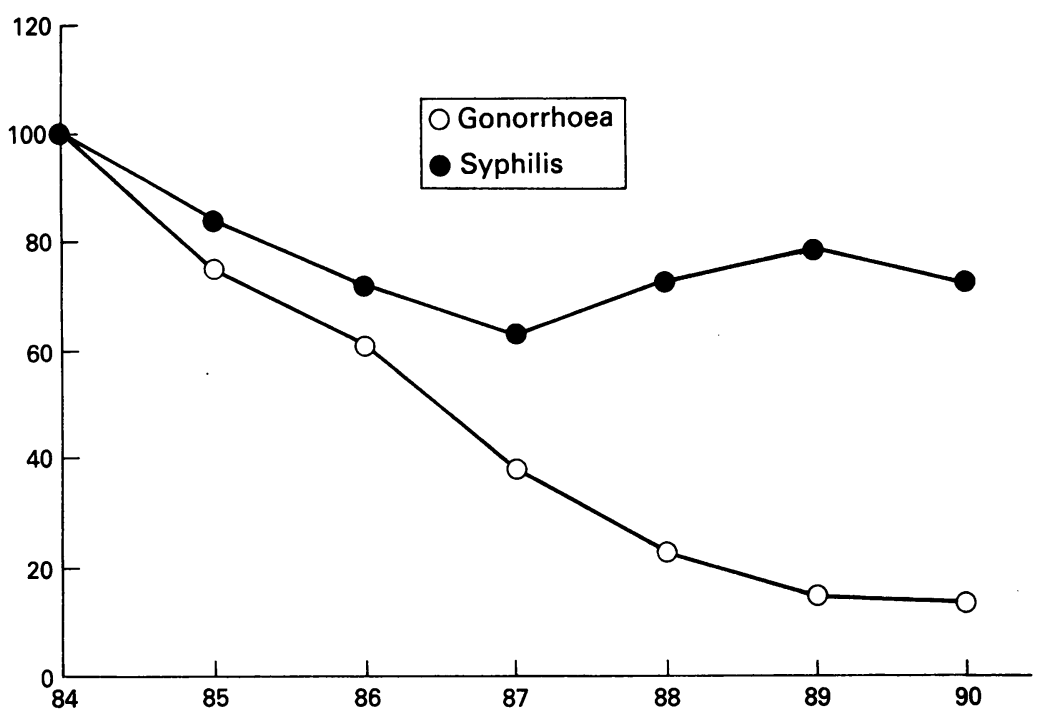

Figure 5 Gonorrhoea, syphilis and chlamydiasis among non-prostitute females, reported by the nursing staffs of STD services during the period 1984-1990, relative to the values in 1984: 1652 with gonorrhoea, 129 with syphilis and 607 with infections due to Chlamydia trachomatis.
Table 3 Number and proportion of heterosexual and homolbisexual males with STD who reported having more than 10 sexual partners

\begin{tabular}{ccl}
\hline Year & Heterosexual males (\%) & Homo-/bisexual males (\%) \\
\hline 1984 & $1978(38 \%)$ & $888(60 \%)$ \\
1985 & $1937(41 \%)$ & $575(57 \%)$ \\
1986 & $1704(42 \%)$ & $311(54 \%)$ \\
1987 & $1104(41 \%)$ & $154(52 \%)$ \\
1988 & $608(31 \%)$ & $86(42 \%)$ \\
1989 & $429(24 \%)$ & $102(35 \%)$ \\
1990 & $494(29 \%)$ & $139(44 \%)$ \\
\hline
\end{tabular}

of patients attending STD services may also vary per STD, the trends presented as well as the relative contribution of the different STDs to the total number of STDs are not representative for the general population. We did not determine whether changes in the subgroups of the registry might be associated with comparable changes in the proportion of these groups in the general population.

The registration of STD is highly dependent on the organisation and activities of STD services. Sometimes changes in reported number of STD may be due to a change in organisation and therefore do not necessarily represent a change in occurrence of STD. Examination of such disrupting factors is needed to unravel the causes of reported changes in incidence. Since the trends of gonorrhoea and syphilis reported by the public health service of Amsterdam ${ }^{6}$ were comparable with the data of the miscellaneous STD services and the notification system, ${ }^{5}$ no evidence exists of changes in organisation of STD services which might have affected the number of reported cases. There is also no evidence for change in reporting of gonorrhoea and syphilis due to changes in diagnostics or treatment in the period 1984-1990. The increased number of Chlamydia trachomatis infections after 1988 however is largely due to the introduction of screening for these infections of all people visiting the STD service of Amsterdam, resulting in improved case-detection. When the data of this STD clinic were excluded from the analysis, no increase in the number of these infections among both males and females was found.

Table 4 Characteristics of patients with chlamydiasis and syphilis compared with those with gonorrhoea

\begin{tabular}{|c|c|c|c|c|c|c|c|c|}
\hline \multirow[b]{2}{*}{ Variable } & \multicolumn{4}{|c|}{ Syphilis compared to gonorrhoea } & \multicolumn{4}{|c|}{ Chlamydiasis compared to gonorrhoea } \\
\hline & Syphilist & Gonorrhoea & OR & $95 \% C I$ & Chlamydiasis\$ & Gonorrhoeał & $O R$ & $95 \% C I$ \\
\hline \multicolumn{9}{|l|}{ Age } \\
\hline $0-19$ & 74 & & & & & & & \\
\hline $20-24$ & 415 & 6565 & 1.60 & $(1 \cdot 24-2 \cdot 07)$ & 2445 & 6463 & $1 \cdot 17$ & $(1 \cdot 06-1 \cdot 30)$ \\
\hline $25-29$ & 626 & 6392 & $2 \cdot 34$ & $(1.82-3.01)$ & 1866 & 6358 & 1.12 & $(1 \cdot 01-1 \cdot 25)$ \\
\hline 30-34 & 605 & 4148 & 3.49 & $(2 \cdot 71-4.50)$ & 1002 & 4161 & 0.98 & $(0.87-1 \cdot 11)$ \\
\hline $35-39$ & 468 & 2710 & 4.28 & $(3 \cdot 30-5 \cdot 54)$ & 501 & 2731 & 0.76 & $(0.67-0.87)$ \\
\hline$>40$ & 344 & 1615 & 5.87 & $(4 \cdot 49-7 \cdot 67)$ & 267 & 1627 & 0.71 & $(0 \cdot 60-0 \cdot 83)$ \\
\hline male & 1658 & 15290 & 1.00 & & 2228 & 15516 & 1.00 & \\
\hline female & 874 & 8024 & $2 \cdot 33$ & $(2 \cdot 08-2 \cdot 62)$ & 4682 & 7937 & $4 \cdot 12$ & $(3 \cdot 87-4 \cdot 42)$ \\
\hline no prostitute & 2060 & 19075 & 1.00 & & 5871 & 19114 & $1 \cdot 00$ & \\
\hline prostitute (female) & 362 & 3581 & 0.76 & $(0.66-0.87)$ & $\begin{array}{r}1021 \\
18\end{array}$ & $\begin{array}{l}3666 \\
673\end{array}$ & $\begin{array}{l}0.40 \\
0.22\end{array}-3-1-3$ & $(0.37-0.44)$ \\
\hline $\begin{array}{l}\text { prostitute (male) } \\
\text { heterosexual }\end{array}$ & $\begin{array}{r}40 \\
1724\end{array}$ & $\begin{array}{r}658 \\
20758\end{array}$ & $\begin{array}{l}2.33 \\
1.00\end{array}$ & $(1.85-2.92)$ & $\begin{array}{r}18 \\
6712\end{array}$ & $\begin{array}{r}673 \\
20856\end{array}$ & $\begin{array}{l}0.22 \\
1.00\end{array}$ & $(0.14-0.35)$ \\
\hline $\begin{array}{l}\text { heterosexual } \\
\text { homosexual }\end{array}$ & 704 & $\begin{array}{r}20758 \\
2284\end{array}$ & $\begin{array}{l}1 \cdot 00 \\
5.29\end{array}$ & & $\begin{array}{r}0112 \\
168\end{array}$ & $\begin{array}{r}20850 \\
2326\end{array}$ & 0.37 & $(0.31-0.44)$ \\
\hline bisexual & 104 & 272 & 6.81 & $(5$. & 30 & 271 & 0.55 & $(0.37-0.81)$ \\
\hline
\end{tabular}

OR = Odds Ratio, $95 \%$-CI = 95\%-confidence interval

*Patients with more than one STD were excluded from the analysi

$\dagger$ Number of patients with syphilis

fNumber of patients with gonorrhoea

$\$ N$ umber of patients with infections due to Chlamydia trachomatis 
Although an overall decline in the number of STDs was found, analysis of subgroups provides more detailed information. Cases of homosexually acquired gonorrhoea infections increased after 1988; among heterosexuals the number of gonorrhoea infections remained constant. With regard to gonorrhoea two epidemics with contrasting patterns of change in the epidemiology could be distinguished: both PPNG and gonorrhoea not caused by penicillinase-producing Neisseria gonorrhoeae increased among homosexual males; among heterosexual males, however, PPNG remained constant while a decrease in the number of gonorrhoea infections not caused by penicillinase-producing Neisseria gonorrhoeae was reported. Among females a strong decrease in the number of gonorrhoea infections not caused by penicillinase-producing. Neisseria gonorrhoeae was reported, together with only a slight decrease in PPNG. An increase in the proportion with PPNG has been demonstrated in Sweden and the United States as well." The findings provide important information since the prevalence of gonorrhoea is known to be directly related to changes in sexual activity and safety measures. ${ }^{12}$ Another indication of changes in sexual activity may be the reported increase in the number of sexual partners among homosexual males. The results with regard to the reported number of sexual partners, however, should be interpreted with caution as this variable is defined as the estimated number of partners during the period of contagiousness of the patient. From the interviews with the nursing staffs of 17 STD services it became evident that patients are generally asked to estimate the number of partmers during the preceding year as the onset of contagiousness may be difficult to determine, especially in cases of syphilis and infections due to Chlamydia trachomatis. The increase in syphilis infections among prostitute females in 1989 was mainly due to the increased number of addicted prostitutes with syphilis as described by van den Hoek et al in $1990 .{ }^{6}$

Finally, the collected data were used to compare the characteristics of patients with different STDs. Although the cases in the registry represent a selected population of STD patients, it is not to be expected that selection by STD has occurred. In other words: homosexuals with STD may visit STD clinics more frequently than their general practitioners but this does not explain the fact that homosexuals in STD clinics are more likely to have syphilis than gonorrhoea. Van den Hoek et al. reported risk factors of Chlamydia trachomatis infection among those attending an STD clinic in Amsterdam. Among other risk factors for Chlamydia trachomatis infections they reported as risk factors for heterosexual males: age $<27$ years, having two or more partners in the preceding half year and for females: age $<26$ years. The prevalence of Chlamydia trachomatis infec- tions was also studied and found to be higher than that of gonorrhoea: among men $14.3 \%$ and $11.5 \%$ and among women $12.9 \%$ and $6.3 \%$ respectively. ${ }^{13}$ In our study patients with infections due to Chlamydia trachomatis were also more likely to be women and of younger age than patients with gonorrhoea. Furthermore, infections due to Chlamydia trachomatis were encountered less frequently than gonorrhoea among prostitute males and prostitute females.

In conclusion, the data provided by STD clinics reveal an epidemiological pattern for STD in the Netherlands. An increase in the total humber of gonorrhoea infections was reported for homosexuals; among heterosexuals the total number of gonorrhoea infections remained constant during the last three years of the study but in this group the proportion with PPNG was found to increase. An increasing number of sexual partners among homosexual males was also reported. These findings suggest that there is a group of highly sexually active individuals who switch to higher risk behaviours and put themselves at risk of STDs. Further research is needed to determine the causes of the described trends and behavioural changes in order to undertake preventive activities.

We thank Martien Sleutjes (HIV Association, formerly with the STD Foundation) and Geert Tillemans (STD Foundation) for their support and helpful comments during this study. We also thank Anneke van den Hoek (Municipal Health Service Amsterdam) for her comments on an earlier version of this manuscript.

1 Walckiers D, Piot P, Stroobant A, Veken van der J, Declerk E. Declining trends in some sexually transmitted diseases in Belgium between 1983 and 1989. Genitourin Med 1991;67:374-7.

2 Catchpole MA. Sexually Transmitted Diseases in England and Wales: 1981-1990. Communicable Disease Report, volume 2, review number 1,1992

3 Greco D, Giuliani M, Suligoi B, Panatta M, Giannetti A. Sexually transmitted diseases in Italy: clinical returns versus statutory notifications. Genitourin Med 1990;66: 383-6.

4 Danielsson D. Gonorrhoea and syphilis in Sweden-past and present. Scand $\mathcal{Y}$ Infect Dis, suppl. 1990;60:69-76.

5 Laar MHW van de, Pickering J, Hoek JAR van den, Griensven GJP van, Coutinho RA, Water HPA van de. Declining gonorrhoea rates in The Netherlands, 1976-88: consequences for the AIDS epidemic. Genitourin Med 1990;66:148-55.

6 Hoek JAR, Linden MMD van der, Coutinho RA. Increase of infections syphilis among heterosexuals in Amsterdam: its relation to drug use and prostitution. Genitourin Med 1990;66:31-2

7 Leenaars PEM, de Weert-van Oene GH, Schrijvers AIP. Circuitkeuze van SOA-patiënten. Rijksuniversiteit Utrecht, Vakgroep Algemene Gezondheidszorg en Epidemiologie, 1989.

8 Laar MJW van de, Water HPA van de. Gonorroe en syfilis in de regio Amsterdam, Leiden: NIPG-TNO, 1987.

9 Davidse W, Treurniet HF. Registratie Seksueel Overdraagbare Aandoeningen. Leiden: NIPG-TNO, 1992.

10 Norusis MJ. SPSS Base System User's Guide. Chicago, 1990.

11 Centers for disease control. Sexually transmitted disease surveillance 1990. Atlanta (GA): US Department of Health and Human Services, public health service, 1991.

12 Hetchcote HW, Yorke JA. Gonorrhea transmission dynamics and control. Lecture notes in biomathematics. Nr. 56. Berlin: Springer, 1984.

13 Hock JAR van den, Haastrecht HJA van, Fennema JSA, Kint JAPCM, Doomum GJ van, Coutinho RA. Vóórkomen en risiof Chlamydia trachomatis bij bezoket Chiamydia trachomats bij bezoekers van een geslachtsziektenpolikliniek in Amsterdam. Ned Tijdschr Geneeskd
1989;133:2392-6. [abstract in English]. 